\title{
CONCISE REVIEWS OF PEDIATRIC INFECTIOUS DISEASES
}

\author{
Carolina Marcus, MD, Gitika Dhillon, MD, and Jennifer H. Anolik, MD, PhD \\ Allergy, Immunology, and Rheumatology Unit, Department of Medicine, University of Rochester \\ School of Medicine and Dentistry
}

\section{Keywords}

B cells; immunodeficiency; autoimmunity; rituximab

B lymphocytes play critical protective roles in maintaining health, including defense against infection and generating an effective response to vaccines. Increasingly, B cells are recognized to actively interact with $\mathrm{T}$ lymphocytes to contribute to antibody-independent protective and pathogenic function; B cells are no longer viewed simply as "antibody factories". Defects in B cell development can be associated with clinical immunodeficiency, whereas a hyperactive B cell compartment may contribute to the development of autoimmune disease, malignant diseases, and transplant rejection.1-7

\section{B CELL DEVELOPMENT}

B cell development is a carefully regulated process that involves the sequential differentiation of hematopoietic stem cell precursors into immature and transitional B cells in the bone marrow, and subsequent maturation to mature naïve and memory subsets occurring in peripheral lymphoid organs (e.g., lymph nodes and spleen) (Table 1; Figure 1). $1-3,8,9$

B cell development begins in the bone marrow with the pluripotent hematopoietic stem cell, which first differentiates into a multipotent progenitor cell. The latter cell interacts with bone marrow stromal cells to differentiate into the common lymphocyte progenitor, which gives rise to both $\mathrm{T}$ cell progenitors and the earliest $\mathrm{B}$-lineage cell, the pro-B cell. Pro-B cells are characterized by the expression of the first B cell-specific surface marker, CD22. Immunoglobulin gene rearrangement begins in pro-B cells; this is a key event in the development of a diverse antibody repertoire. The recombinase-activating gene-encoded enzymes, RAG1and RAG2, are essential for this process, as well as for T cell receptor gene rearrangement in T cells; thus, RAG mutations lead to a form of severe combined immunodeficiency. The next developmental stage, the pre-B cell, is characterized by the completed rearrangement of the heavy $\mu$ chain paired with the surrogate light chain on the cell surface (termed the pre-B cell receptor), along with expression of CD19 and later CD20. The pre- $\mathrm{B}$ cell receptor $(\mathrm{BCR})$ is a critical checkpoint for the regulation of $\mathrm{B}$ cell development, since its expression and functional signaling are required for cell expansion

Corresponding author: Jennifer Anolik, MD, PhD, Associate Professor of Medicine, University of Rochester School of Medicine and Dentistry, 601 Elmwood Ave. Box 695, Rochester, NY 14642, TEL 585-341-7900, jennifer_anolik@urmc.rochester.edu.

Publisher's Disclaimer: This is a PDF file of an unedited manuscript that has been accepted for publication. As a service to our customers we are providing this early version of the manuscript. The manuscript will undergo copyediting, typesetting, and review of the resulting proof before it is published in its final citable form. Please note that during the production process errors may be discovered which could affect the content, and all legal disclaimers that apply to the journal pertain. 
and further differentiation. The X chromosome-encoded cytoplasmic Bruton's tyrosine kinase (BTK) plays a key role in pre-BCR signaling.

Successful light chain recombination characterizes progression to the immature B cell stage, allowing surface expression of complete IgM molecules. This is another defining moment in the life of the B cell; from now on, its development is dependent upon cognate recognition of antigen. Antigen-specific negative selection, receptor editing, and clonal deletion begin to control autoreactivity (i.e., "immune tolerance to self" is established). Despite the typical apoptosis of autoreactive B cells in the bone marrow, a significant fraction of them may proceed unchecked into the peripheral repertoire, creating the need for additional censoring at later stages.10, 11 Although more than $10^{7} \mathrm{~B}$ cell precursors begin their development each day, only a few percent will survive and emerge into the peripheral blood as transitional B cells (Figure 1).

After passing the transitional stage, the human mature B cell compartment consists of multiple cell populations including circulating B cells, follicular naïve, marginal zone, and diverse memory cell subsets.12, 13 Mature B cells express surface IgM, IgD, CD19, and $\mathrm{CD} 20$; their survival depends upon recognition of their cognate antigen and subsequent differentiation. Naïve follicular B cells that are successfully activated by antigen and T cellderived signals in spleen or lymph node can give rise to the GCs, specialized structures crucial for class switch recombination (CSR) and somatic hypermutation (SHM), which in turn are responsible for the acquisition of different immunoglobulin isotypes, increased antigen specificity, and long-lived memory and plasma cell generation. Memory B cells are marked by surface expression of CD27.

\section{B CELL ABNORMALITIES IN DISEASE}

\section{Primary Immunodeficiencies}

The more common B cell immunodeficiencies are manifested by defects in antibody production, generally (but not invariably) associated with increased susceptibility to infections.2, 5, 6 Selective IgA deficiency is the most common form of primary immune deficiency in the Western world (approximate frequency 1:700 individuals worldwide). The serum concentrations of the other immunoglobulins are normal, and only about $33 \%$ of patients with selective IgA deficiency are prone to infections. No specific therapy for IgA deficiency exists, but attention to recurrent sinopulmonary infection with antibiotic therapy and an avoidance of environmental risk factors for gastrointestinal parasites (i.e., Giardia, Cryptosporidium) is indicated. Deficiencies of IgG subclasses may be associated with frequent infections, but many IgG subclass-deficient children simply have delayed maturation and eventually achieve adult serum concentrations.

Common Variable Immunodeficiency (CVID) refers to a heterogeneous group of disorders (likely each with its own, as of yet undefined, genetic cause) that are characterized by defective antibody production, and it is the most common primary immunodeficiency that comes to medical attention (approximate incidence 1:75,000 births). Serum concentrations of all immunoglobulin isotypes typically are low, though occasionally only IgG is deficient; cell-mediated immunity is sometimes deficient as well. Various modes of inheritance have been reported, but sporadic cases are most common. Most CVID patients present in the second or third decade of life, but young children may present with it as well. Up to 25-30\% of patients with CVID develop granulomatous lung and skin disease. Most infections in patients with CVID are sinopulmonary or gastrointestinal in nature. In general, a combination of IgG replacement and antibiotics are employed in the therapy of CVID. 
Agammaglobulinemias are rare antibody deficiencies caused by defects in early B cell development and characterized by low or absent B cells ( $<2 \%$ in the peripheral blood), severe hypogammaglobulinemia, and increased susceptibility to infections (particularly with extracellular pyogenic bacteria). Bruton's X-linked agammaglobulinemia (XLA) is caused by mutations in the $b t k$ gene, leading to arrest of $\mathrm{B}$ cell development at the pre-B cell stage. It is the most common form of agammaglobulinemia (85\% of all agammaglobulinemias; incidence 1:400,000 live births, or 1:200,000 males). Historically, Bruton's XLA was the first immunodeficiency to be characterized at the genetic level. Life-long IgG replacement (with either IVIG or subcutaneous IgG) has converted this illness from a condition fatal in early childhood to a chronic one compatible with long-term survival.

The hyper-IgM syndrome (HIM) represents a group of distinct entities characterized by normal or elevated levels of IgM together with diminished levels of $\operatorname{IgG}$ and $\operatorname{IgA}$, representing a failure of isotype switch in B cells. The most common type of HIM is classified as HIM1; it is caused by mutations in the gene on the $\mathrm{X}$ chromosome which encodes the CD40 ligand (CD40L, also known as CD154).2, 5, 6 These boys typically have a history of recurrent pyogenic infections, and are also very susceptible to Pneumocystis pneumonia. Hematopoietic stem cell transplantation is therapeutic in X-linked HIM. HIM1 is a rare condition, with an approximate incidence of 1:1,000,000 live births (1:500,000 males). Other even rarer forms of HIM are inherited in an autosomal recessive fashion; these include deficiencies in enzymes required for SHM and CSR, or in CD40 itself (i.e., HIM2, HIM4, and HIM5 from deficiencies in activation-induced deaminase [AID], uracil DNA glycosylase [UNG], and unknown enzyme[s], and HIM3 from CD40 deficiency].

Finally, although not a primary immunodeficiency in the usual sense of the word, a maturational defect in certain B cell subsets in the blood and/or the spleen is postulated to contribute to the increased susceptibility to encapsulated bacterial disease in young children, and the associated decreased polysaccharide vaccine antibody response. The development of protein-polysaccharide conjugate vaccines to sidestep this decreased immunologic response to polysaccharides in young children has revolutionized pediatric infectious diseases and general pediatric practice.

\section{Autoimmunity}

Another potential consequence of dysregulation of B cell development and selection is the induction of autoimmunity. As noted earlier, autoreactive B cells naturally arise during the process of immunoglobulin gene rearrangement and must be properly censored (tolerance). Systemic lupus (SLE) is a disease characterized by well-recognized defects in B cell tolerance and homeostasis.14 Although human SLE is polygenic, it is instructive that lupus can develop in the mouse from B cell signaling defects that lead to a hyperactive B cell compartment and loss of tolerance. 15 In human SLE, expansions of circulating memory (CD27+) B cells, plasmablasts, and transitional B cells have all been described in the peripheral blood.16, 17 Thus, B cell signaling is likely important in the breakdown of B cell tolerance and the pathogenesis of lupus.

\section{THERAPEUTIC MANIPULATION OF B CELLS}

Given the pathogenic role of B cells in malignancy and autoimmunity, a number of strategies have recently emerged to modify the B cell compartment as a disease treatment. The approaches that are currently available or in development include: direct killing using of B cells via B cell-depleting monoclonal antibodies; inhibition of cytokines involved in B cell survival or differentiation (or both); induction of negative signaling in B cells; interruption of signaling through the BCR or co-stimulatory receptors; and deletion or functional inactivation of antigen-specific autoreactive B cells.7, 18 B cell depletion with the chimeric 
anti-CD20 monoclonal antibody rituximab is widely used for the treatment of non-Hodgkin follicular lymphoma (NHL). It is estimated that close to one million lymphoma patients have been treated with rituximab since the drug was FDA-approved in 1997.19 More recently, rituximab also has been approved for the treatment of rheumatoid arthritis refractory to TNF blockade, and has proven effective in randomized placebo controlled trials of relapsing-remitting multiple sclerosis, type 1 diabetes, and other refractory autoimmune diseases.20, 21 Newer human or humanized anti-CD20 monoclonal antibodies may become even more widely utilized in the future (e.g., ofatumumab, ocrelizumab).

In many autoimmune diseases, such as systemic lupus erythematosus, clinical benefits of anti-CD20 B cell depletion accrue despite the fact that serum autoantibody concentrations do not decline.16, 22 Overall, these findings support the emerging concept that B cells also play antibody-independent roles in the immune system, including cytokine secretion and modulatory effects upon T cells and dendritic cells.23-25 Importantly, the incidence of infections generally is not increased after B cell depletion, and total serum immunoglobulins and protective antibody levels typically remain normal. This is because antibodies are predominantly secreted by long-lived plasma cells, which do not express surface CD20. However, rare cases of infectious complications and severe antibody deficiency have been described, as has a prolonged paucity of memory B cells in some patients after B cell depletion therapy.26, 27

\section{REFERENCES}

1. Vale AM, et al. Clinical consequences of defects in B cell development. J Allergy Clin Immunol. 2010; 125:778-787. [PubMed: 20371392]

2. Chaplin DD. Overview of the immune response. J Allergy Clin Immunol. 2010; 125:S3-S23. [PubMed: 20176265]

3. LaRosa DF, et al. Lymphocytes. J Allergy Clin Immunol. 2008; 121:S364-S369. [PubMed: 18241683]

4. Schroeder HW, et al. Structure and function of immunoglobulins. J Allergy Clin Immunol. 2010; 125:S41-S52. [PubMed: 20176268]

5. Notarangelo LD. Primary immunodeficiencies. J Allergy Clin Immunol. 2010; 125:S182-S194. [PubMed: 20042228]

6. Bonilla FA, et al. Practice parameter for the diagnosis and management of primary immunodeficiencies. Ann Allergy Asthma Immunol. 2005; 94:S1-S63. [PubMed: 15945566]

7. Ahmed S, et al. B-cell biology and related therapies in systemic lupus erythematosus. Rheum Dis Clin North Am. 2010; 36:109-130. [PubMed: 20202594]

8. Cancro M. Peripheral B cell maturation...selection and homeostasis. Immunol Rev. 2004; 197:89101. [PubMed: 14962189]

9. Carsetti R, et al. Peripheral development of B cells in mouse and man. Immunol Rev. 2004; 197:179-191. [PubMed: 14962195]

10. Goodnow CC, et al. Self-tolerance...in B lymphocyte development. Adv Immunol. 1995; 59:279_ 368. [PubMed: 7484462]

11. Wardemann H, et al. Predominant autoantibody production by ...human B cell precursors. Science. 2003; 301:1374-1377. [PubMed: 12920303]

12. Palanichamy A, et al. Novel human transitional B cell populations. J Immunol. 2009; 182:59825993. [PubMed: 19414749]

13. Sanz I, et al. Phenotypic and functional heterogeneity of...memory B cells. Seminars Immunol. 2008; 20:67-82.

14. Anolik J, et al. B cells in...systemic lupus erythematosus. Curr Opin Rheumatol. 2004; 16:505512. [PubMed: 15314486]

15. Anolik JH. B cell biology and dysfunction in SLE. Bull NYU Hosp Jt Dis. 2007; 65:182-186. [PubMed: 17922667] 
16. Anolik JH, et al. Rituximab improves peripheral B cell abnormalities in...systemic lupus erythematosus. Arthritis \& Rheumatism. 2004; 50:3580-3590. [PubMed: 15529346]

17. Odendahl M, et al. Disturbed peripheral B lymphocyte homeostasis in systemic lupus erythematosus. J Immunol. 2006; 165:5970-5979. [PubMed: 11067960]

18. Sanz I, et al. B cells as therapeutic targets in SLE. Nat Rev Rheumatol. 2010; 6:326-337. [PubMed: 20520647]

19. Sanz I, et al. B cell depletion therapy in autoimmune diseases. Front Biosci. 2007; 12:2546-2567. [PubMed: 17127262]

20. Hauser SL, et al. B-cell depletion with rituximab in relapsing-remitting multiple sclerosis. N Engl J Med. 2008; 358:676-688. [PubMed: 18272891]

21. Pers JO, et al. B-cell depletion...in autoimmune diseases. Clin Rev Allergy Immunol. 2008; 34:50-55. [PubMed: 18270858]

22. Looney RJ, et al. B cell depletion...for systemic lupus erythematosus.... a trial of rituximab. Arthritis \& Rheumatism. 2004; 50:2580-2589. [PubMed: 15334472]

23. Sfikakis PP, et al. Remission of...lupus nephritis following B cell depletion...preceded by downregulation of CD40 ligand. Arthritis \& Rheumatism. 2005; 52:501-513. [PubMed: 15693003]

24. Stasi R, et al. Analysis of regulatory T-cell changes in patients...receiving B cell-depleting therapy with rituximab. Blood. 2008; 112:1147-1150. [PubMed: 18375792]

25. McFarland HF, et al. The B cell—old player, new position on the team. N Engl J Med. 2008; 358:664-665. [PubMed: 18272890]

26. Anolik JH, et al. B cell reconstitution after rituximab...recapitulates B cell ontogeny. Clin Immunol. 2007; 122:139-145. [PubMed: 17008130]

27. Walker AR, et al. Profound hypogammaglobulinemia 7 years after treatment for indolent lymphoma. Cancer Invest. 2008; 26:431-433. [PubMed: 18443965] 


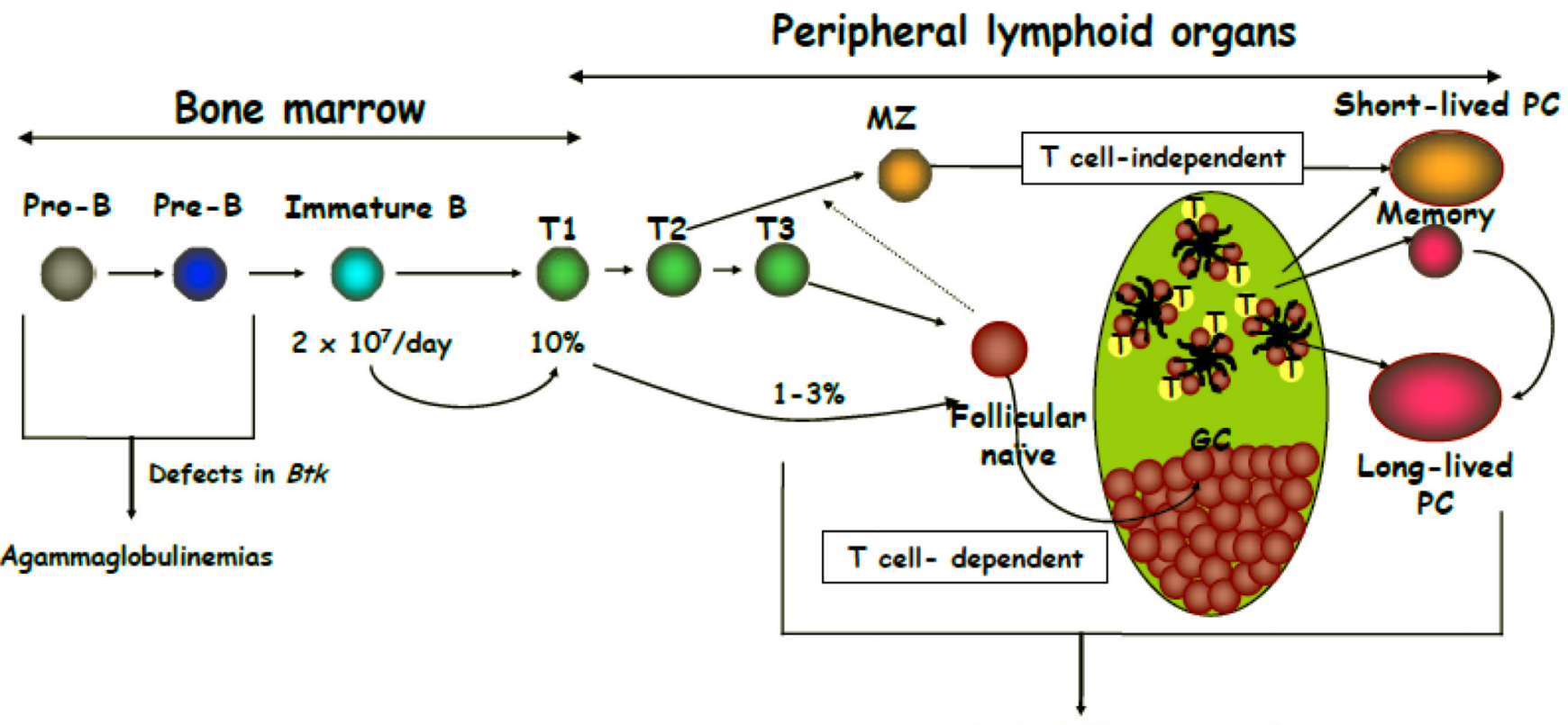

HIMS, CVID, selective IgA deficiency

FIGURE 1.

Overview of B cell development (see text for details and abbreviations). 


\section{TABLE 1}

Development of the B cell lineage.*

\begin{tabular}{lcccc}
\hline Characteristic & Pro-B Cell & Pre-B Cell & Immature B Cell & Mature B Cell \\
\hline Location & Bone marrow & Bone marrow & Lymph node, spleen & Lymph node, spleen \\
\hline DNA Rearrangement & $\mu$-chain & Light chain & Complete BCR & $\begin{array}{c}\text { Class switch recombination, somatic } \\
\text { hypermutation }\end{array}$ \\
\hline Antigen Interaction & None & None & $\begin{array}{c}\text { Yes-deletion of autoreactive } \\
\text { clones, receptor editing }\end{array}$ & $\begin{array}{c}\text { Yes-survival and development is } \\
\text { antigen-dependent }\end{array}$ \\
\hline Membrane IgG & None & $\mu+$ surrogate light \\
chain & IgM & IgM, IgD & CD19, CD20 \\
\hline Selected Surface Markers & CD22 & CD19 & CD19, CD20 & \\
\hline
\end{tabular}

Excluding the earlier progenitors and the subsequent CD27-expressing memory cells and plasma cells 